\section{Nauplius}

The Journal of The

Brazilian Crustacean Society

e-ISSN 2358-2936

www.scielo.br/nau www.crustacea.org.br

\title{
First record of a tantulocaridan, Microdajus sp. (Crustacea: Tantulocarida), from the northwestern Atlantic
}

\author{
Christopher B. Boyko ${ }^{1,2}$ (D) orcid.org/0000-0002-2205-1488
}

Jason D. Williams' (1) orcid.org/0000-0001-5550-9988

Adelaide Rhodes ${ }^{3}$ (1) orcid.org/0000-0002-1714-1972
${ }^{1}$ Hofstra University, Department of Biology. Hempstead, New York 11549, United States of America.
CBB E-mail: christopher.b.boyko@hofstra.edu
JDW E-mail: jason.d.williams@hofstra.edu
2 American Museum of Natural History, Division of Invertebrate Zoology. New York, New York, 10024, United States of America.
CBB E-mail: cboyko@amnh.org
${ }^{3}$ LifeMine Therapeutics. Cambridge, Massachusetts 02140, United States of America. AR E-mail: adelaide.rhodes@gmail.com

ZOOBANK: http://zoobank.org/urn:lsid:zoobank.org:pub:B11C7CED-041A-4D9FBDF0-3C95B4A34975

\section{Abstract}

A putative new species of tantulocaridan is reported parasitizing a species of typhlotanaid (Tanaideacea) from the Gulf of Mexico at depths up to $2767 \mathrm{~m}$. The tantulocaridan belongs to Microdajus Greve, 1965, species of which are all known from tanaid hosts in the superfamily Paratanoidea. Tantulocaridan samples included newly settled tantulus larvae, early stages of trunk development and developing males; parasites were found attached to anterior appendages (antennules and pereopods) or bodies of hosts. This material likely represents a new species but the condition and number of available specimens precludes a formal description. The putative new species is most similar to Microdajus aporosus Grygier and Sieg, 1988 and Microdajus tchesunovi Kolbasov and Savchenko, 2010 in having an endopodal seta on each of the sixth thoracopods (lacking in other species). Microdajus tchesunovi is the only described species of Microdajus with males bearing unsegmented sixth thoracopod protopods; this character is also found on the present specimens. Males of the newly reported tantulocaridan can be distinguished from those of $M$. tchesunovi based on protopod 1-5 morphology and setation of the pits on the cephalothorax (fewer setae in males of the western Atlantic specimens compared to M. tchesunovi). This is the first species of Microdajus reported from the western Atlantic and the first tantulocaridan known from the Gulf of Mexico or northwestern Atlantic.

\section{KEYWORDS}

Gulf of Mexico, Multicrustacea, parasite, tantulus larva, Typhlotanaidae 


\section{INTRODUCTION}

Tantulocaridans are ectoparasitic crustaceans with a complex and incompletely known life cycle (Huys et al., 1993; Martinez Arbizu and Petrunina, 2017; Petrunina et al., 2018) that use a variety of other crustaceans, such as ostracods, copepods, isopods, tanaids, and amphipods, as their hosts (Grygier and Sieg, 1988; Boxshall and Vader, 1993; Ohtsuka and Boxshall 1998). Currently, there are 39 described species belonging to 23 genera and five families (Petrunina and Huys, 2020; Walter and Boxshall, 2020). The most speciose genera are Microdajus Greve, 1965 and Tantulacus Huys, Andersen and Kristensen, 1992, with five species in each (Walter and Boxshall, 2020). The hosts for all described species in Microdajus are tanaids whereas none of the hosts are known from any Tantulacus species as only free larvae have been collected, principally from meiofaunal samples. Tantulocaridans as a whole have been reported with a world-wide distribution (Mohrbeck et al., 2010) but only two species, Tantulacus coroniporus Martinez Arbizu and Petrunina, 2017 and Aphotocentor kolbasovi Petrunina and Huys, 2020, have been described from the entire western Atlantic, specifically from the Argentinian abyssal plain (Martinez Arbizu and Petrunina, 2017) and the Campos Basin, Brazil (Petrunina and Huys, 2020). In the present paper, we report the first species of tantulocaridan reported from the northwestern Atlantic, which is also the first tantulocaridan reported from the western Atlantic with a tanaid host.

\section{Material and Methods}

Parasites were documented with a Nikon Eclipse E200 digital camera affixed to a compound microscope. Line drawings were made by tracing light and scanning electron micrographs or sketching specimens using a drawing tube attached to an Olympus CX31 compound microscope. Adobe Illustrator and Photoshop were used to produce final figures. For SEM preparation, specimens were dehydrated in an ascending ethanol $(\mathrm{EtOH})$ series ( $70 \% \mathrm{EtOH}$ to $100 \% \mathrm{EtOH})$. Specimens were then dried in a Samdri 795 Critical Point Dryer, mounted on aluminum stubs, coated with gold using an EMS-
550 Sputter coater, and viewed with a FEI Quanta 250 SEM.

Measures of hosts (total length including antennules) and parasites were made based on slide microscales or SEM micrographs. Some station data for hosts was obtained from Montagna et al. (2013: supplemental Table 1). During the process of photographing the attached tantulus larva, the trunk became detached from the cephalon and lost. Fortunately, the cephalon was retained and prepared for SEM; characters for the tantulus were derived from a combination of the light and electron micrographs but some are in need of further study with new material. In addition, one specimen with a developing male was desiccated during transfer from a vial to a slide; most structures had already been observed but some, such as the precise number of aesthetascs, remain unknown. Three other specimens listed under Material Examined were only observed in photographic images. The term "neuter" for tanaids refers to the first juvenile (post-manca) stage. All specimens are deposited in the National Museum of Natural History, Smithsonian Institution, Washington D.C., USA (USNM). References are provided for taxonomic authorities of parasite taxa but not for hosts.

\section{Systematics}

Family Microdajidae Boxshall and Lincoln, 1987

Genus Microdajus Greve, 1965

\section{Microdajus sp. \\ (Figs. 1-2)}

Material examined (measured specimens so noted). Early expanded tantulus larva bearing trunk sac $(108 \mu \mathrm{m})$ attached to antennule of neuter Typhlotanais sp. $(1.2 \mathrm{~mm})$ (on SEM stub; USNM 1640971, Fig. 2A, B), 26.9997, -87.9967, Gulf of Mexico, 2767 m, coll. R/V Gyre, 20 Sept 2010. Head of tantulus larva (body lost) (24 $\mu \mathrm{m}$ head length; ca. $58 \mu \mathrm{m}$ total length), attached to left side of body between second and third pereomeres of neuter Typhlotanais sp. $(877 \mu \mathrm{m})$, same collection data as above (on SEM stub; USNM 1640972, Fig. 1E, F). Expanded tantulus larva with 
developing male $(245 \mu \mathrm{m})$ attached to right pereopod 1 of neuter Typhlotanais sp. (1.0 mm) (on SEM stub; USNM 1640973, Fig. 2C-F), 28.4479, -89.6719, Gulf of Mexico, 684 m, coll. R/V Gyre, 13 Oct 2010. Expanded tantulus larva with developing male $(330 \mu \mathrm{m}$ total length) and tantulus larva with very early trunk sac (90 $\mu \mathrm{m})$, attached to left first pereopod of male Typhlotanais sp. (1.5 mm), 28.4479, -89.6719, Gulf of Mexico, 684 m, coll. R/V Gyre, 13 Oct 2010 (USNM 1640974, photographic specimens 2671.1, 2671.2, Fig. 1A-D).
Expanded tantulus larva with developing male, attached to right pereopod of male Typhlotanais sp., Gulf of Mexico (precise locality unknown) (photographic specimen 2672). Expanded tantulus larvae with early parthenogenetic sac, attached to right antennule of neuter Typhlotanais sp., Gulf of Mexico (precise locality unknown) (photographic specimen 2673). Tantulus larva, attached to right antennule of neuter Typhlotanais sp., Gulf of Mexico (precise locality unknown) (photographic specimen 2675).

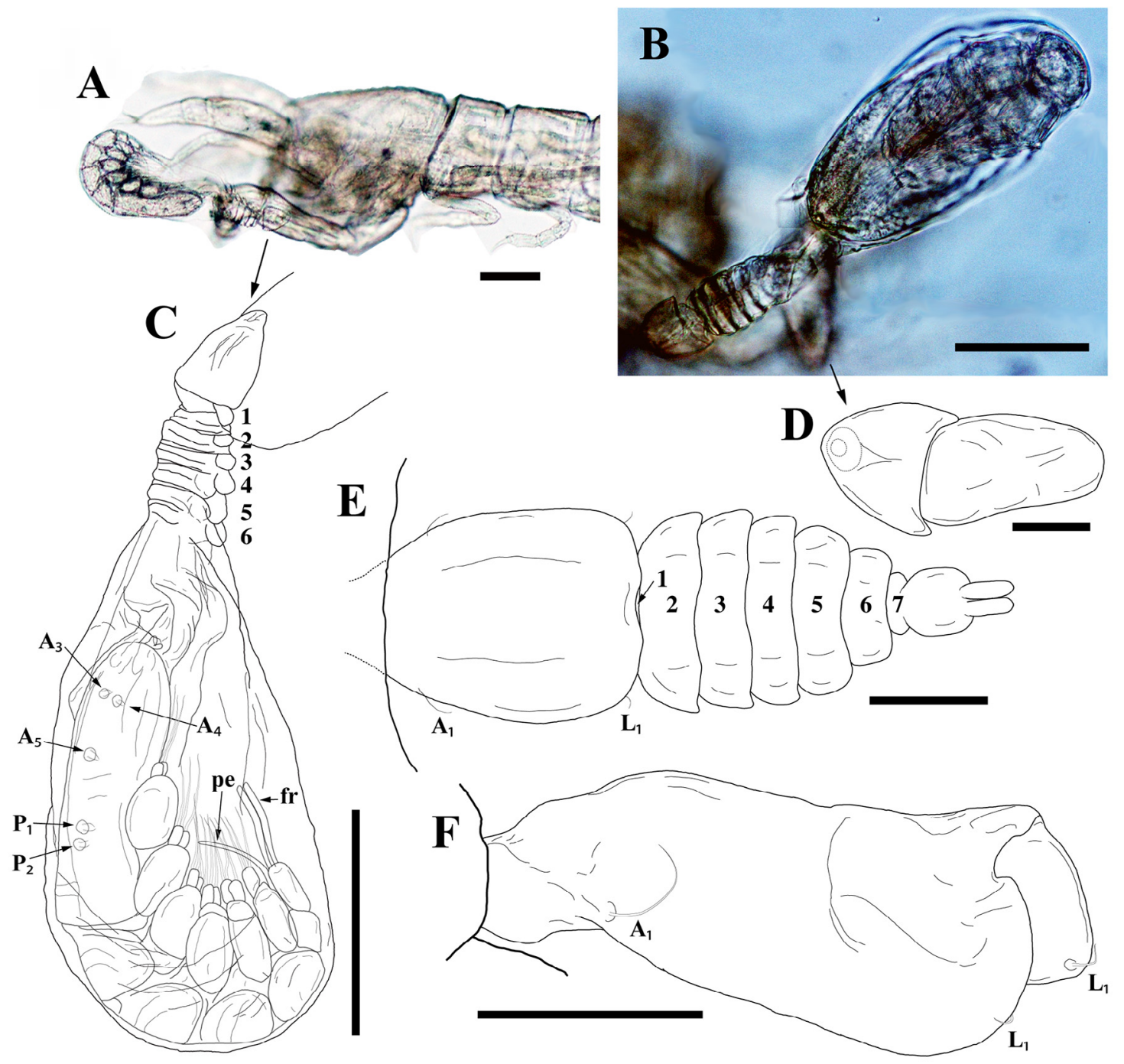

Figure 1. Microdajus sp. A) Expanded tantulus larva, lateral view, with developing male (330 $\mu \mathrm{m})$ attached to pereopod 1 of male Typhlotanais sp. (USNM 1640974, photographic specimen 2671.1). B) Expanded tantulus larva, dorsal view, with developing male inside trunk sac, ventral view (male rotated relative to larva) (USNM 1640974, photographic specimen 2671.1). C) Expanded tantulus larva with developing male inside trunk sac, lateral view (USNM 1640974, photographic specimen 2671.1). D) Expanded tantulus bearing early trunk sac, dorsal view (body outline only, no setae drawn; oral disc observed through cephalon shown in dashed line) (USNM 1640974, photographic specimen 2671.2). E) Tantulus larva, dorsal view (traced from light and SEM images; USNM 1640972). F) Cephalon of tantulus larva, lateral view (traced from SEM image; USNM 1640972). Abbreviations: $A_{1}, A_{3}-A_{5}, L_{1}, P_{1}$, $\mathrm{P}_{2}=$ cephalic pores with setae; fr $=$ furcal rami; pe = penis. Scales $=100 \mu \mathrm{m}(\mathrm{A}-\mathrm{C}) ; 25 \mu \mathrm{m}(\mathrm{D}) ; 10 \mu \mathrm{m}(\mathrm{E}, \mathrm{F})$. 

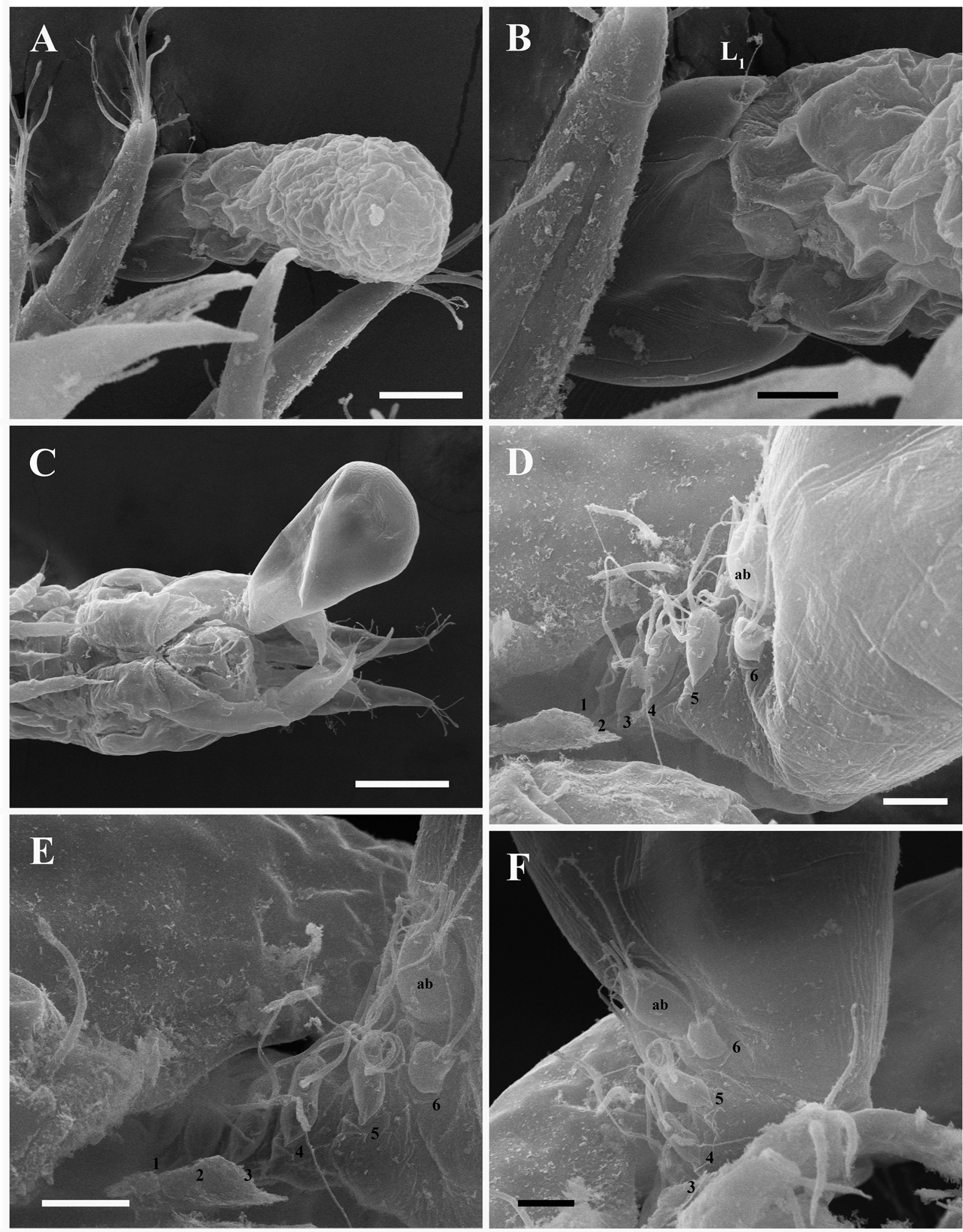

Figure 2. Microdajus sp. A, B) Expanded tantulus larva bearing trunk sac attached to right antennule of neuter Typhlotanais sp. (1.2 $\mathrm{mm}$ ) (USNM 1640971). C-F) Expanded tantulus larva bearing male in sac attached to right pereopod 1 of neuter Typhlotanais sp. (1.2 mm) (USNM 1640973). A) Ventral view. B) Cephalon showing $L_{1}$ cephalic pore with long setae. C) Ventral view. D-E) Thoracopods 1-6 and abdominal segments, oblique view. F) Thoracopods 3-6 and abdominal segments, lateral view. Abbreviations: $1-6$ refer to thoracopods; $a b=$ abdomen. Scales $=25 \mu \mathrm{m}(\mathrm{A}) ; 10 \mu \mathrm{m}(\mathrm{B}, \mathrm{D}-\mathrm{F}) ; 100 \mu \mathrm{m}(\mathrm{C})$. 
Description of tantulus larva. Body comprised of cephalon, 6 limb-bearing thoracic segments, and twosegmented urosome (Fig. 1E). Total length $58 \mu \mathrm{m}$ for tantulus larva prior to development of trunk sac (Fig. 1E). Cephalon triangular, tapering anteriorly, $\sim 24 \mu \mathrm{m}$ long $\times 18 \mu \mathrm{m}$ wide (Fig. 1E). Cephalic shield smooth, with two long mediodorsal longitudinal lamellae (Fig. 1E). Cephalic pore formula $\mathrm{A}_{\mathrm{I}}, \mathrm{L}_{\mathrm{I}}$; both sets of pores bearing setae; $\mathrm{A}_{\mathrm{I}}$ setae more than twice as long as $\mathrm{L}_{\mathrm{I}}$ setae (Fig. 1E, F). Ventral surface of cephalon without pores, smooth. Trunk segments 1-7 with distinct tergites (Fig. 1E) lacking ornamentation. First tergite narrow, almost entirely concealed under cephalic shield (Fig. 1E), more visible in metamorphosed tantulus containing developing male (Fig. 1B, C). Tergite 2 widest, width of the following tergites gradually decreasing posteriorly until tergite 6 , tergite 7 (first segment of urosome) approximately half the width of preceding tergite. Urosome consisting of two unequal segments ( $2 \mu \mathrm{m}$ and $6 \mu \mathrm{m}$ long) (Fig. 1E). First segment (seventh trunk segment) smooth, without ornamentation; approximately half width of tergite 6 (Fig. 1E). Second segment (abdomen) dorsally smooth. Furcal rami each with one terminal seta, longer than wide (Fig. 1E), length subequal to length of terminal urosome segment (two outer lateral setae not visible in light micrographs).

Description of tantulus larva with early parthenogenetic sac. (Figs. 1D, 2A, B). Body comprised of smooth, triangular cephalon (Fig. 2A, B) and rounded trunk; trunk 2-3 times longer than cephalon, with wrinkled appearance (Fig. 2A, B). $90 \mu \mathrm{m}$ total length of tantulus larva with very early trunk sac (Fig. 1D); $108 \mu \mathrm{m}$ for tantulus larva with early trunk sac (Fig. 2A). Cephalic shield as in tantulus larva; other segments lacking.

Description of tantulus larva with early male sac. (Fig. 2C-F). Cephalon as described above, trunk expanded toward posterior end (approximately 2 times wider at distal end than base), rounded posterior end, lacking wrinkled appearance of early parthenogenetic sac (Fig. 2C); $250 \mu \mathrm{m}$ total length. Thoracic segments 1-6 bearing biramous thoracopods without medial endites (Fig. 2D-F). Thoracopods 1-5 subequal in size and shape; protopods subrectangular, wider than long, each extending to acute point on lateral margin; rami situated on mesial side of protopods; each a small, stub-shaped segment bearing single elongate serrate seta; endopodal and exopodal setal length and width subequal, each endopodal seta of thoracopods 2-5 with large, mesial spine one-third of distance from base of seta (Fig. 2D-F). Thoracopod 6 with cylindrical protopod, ramal segments reduced, exopod more than twice as long and wide as endopod, each endopod with one seta (Fig. 2D-F). Urosome of two unequal segments; first segment (seventh trunk segment) minute; second segment (abdomen) cylindrical with smooth surface, approximately twice the size of thoracopod 6 (Fig. 2D-F). Furcal rami distinct, longer than wide, each bearing one short smooth terminal seta with truncate distal margin and two lateral serrate tapering setae, larger seta greater than three times as long as smaller seta (Fig. 2D-F).

Description of male (Fig. 1A-C). All studied males were inside trunk sacs; length of complete specimens (cephalothorax and trunk sac) measured to 330 $\mu \mathrm{m}$ (Fig. 1A), total body length of male inside sac approximately $285 \mu \mathrm{m}$ (if straightened). Trunk sac with developing male formed posterior to sixth thoracic tergite (Fig. 1A-C). Larval tergites separated from appendages by slight thoracic expansion, abdomen deflected ventrally (Fig. 1A, B). Male inside sac connected to host via umbilical cord passing through attached larva (Fig. 1C). Cephalothorax (129 $\mu \mathrm{m}$ long) includes first and second limb-bearing segments, followed by four free limb-bearing thoracic and two abdominal segments (Fig. 1A, B). Cephalic shield smooth, with seven pairs of pits containing from one to two setae (Fig. 1C) arranged in five anterior (A1A5) and two posterior (P1, P2) pairs; A1, A2 setal counts indeterminate, A3, A4 with one seta each, A5, P1, P2 with two setae each. Cephalothorax with aesthetascs at anterior margin; other appendages lacking. First two thoracic segments fused with cephalon, bearing two pairs of biramous thoracopods. Tergites of following thoracic segments each with two lineae across surface (Fig. 1B). Thoracopods 1-3 each comprised of large unsegmented protopod and one-segmented ramus; thoracopod 1 exopod slightly longer than endopod. Thoracopods 4 and 5 each with two-segmented protopod comprised of small basis and larger coxa (Fig. 1C). Thoracopod 6 uniramous, with unsegmented protopod; distal segment (exopod?) with long subequal terminal setae and shorter outer seta. All thoracopods with long 
terminal setae; precise setal counts unclear. First abdominal segment approximately $17 \mu \mathrm{m}$ long. Second abdominal segment (telson; $26 \mu \mathrm{m}$ long) bearing furcal rami approximately $37 \mu \mathrm{m}$ long (Fig. 1B). Penis approximately $38 \mu \mathrm{m}$ long, recurved.

Remarks. Due to the lack of adequate specimens, we cannot describe the present material as a new species, although it is likely to be so. However, sufficient characters were examined in the photomicrographs and in the extant specimens that we can make comparisons with the described species of Microdajus. We have identified these specimens as belonging to Microdajus because all species in this genus have one or two anterior cephalic pores, whereas the sole species of Xenalytus Huys, 1991 has three anterior pores.

The tantulus larvae of Microdajus sp. from the Gulf of Mexico differ from four of the other five described species in the genus in having a total of two cephalic pores: $A_{I}$ and $L_{I}$. The only other species with so few pores is Microdajus aporosus Grygier and Sieg, 1988, which likewise has $\mathrm{A}_{\mathrm{I}}$ and $\mathrm{L}_{\mathrm{I}}$. Grygier and Sieg (1988: fig. 9) included arrows pointing to pores at the anterior margin and ventral posterior corners of the carapace of $M$. aporosus, indicating that these pores are indeed $\mathrm{A}_{\mathrm{I}}$ and $\mathrm{L}_{\mathrm{I}}$, not $\mathrm{D}_{\mathrm{I}}$ and $\mathrm{L}_{\mathrm{I}}$ as stated by Kolbasov and Savchenko (2010). Microdajus sp. differs from M. aporosus in having a long seta arising from each $\mathrm{A}_{\mathrm{I}}$ pore (pore without long seta in M.aporosus). However, the position of the anterior pore is different in these species, being positioned considerably farther from the anterior end and more laterally on the cephalon in Microdajus sp. than in $M$. aporosus, where it is nearly at the tip and more dorsally positioned (compare Fig. 1E, F herein with Grygier and Sieg, 1988: figs. 6,9); this suggests than these " $A_{I}$ " pores may not be homologous in the two species.

Microdajus sp. is most similar to M. aporosus and Microdajus tchesunovi Kolbasov and Savchenko, 2010 in having an endopodal seta on each of the sixth thoracopods; the other three species in Microdajus lack endopodal setae. The present material is also similar to M. aporosus, M. tchesunovi, and Microdajus gaelicus Boxshall and Lincoln, 1987 in lacking medial endites on the thoracopods; the other two species in the genus possess endites (see table 1 in Kolbasov and Savchenko, 2010). The abdomen of Microdajus sp. does not appear to bear any denticles whereas that of $M$. tchesunovi bears minute, irregular denticles; the other species in the genus either have long patterned denticles or the character state is unknown (see table 1 in Kolbasov and Savchenko, 2010).

The male of Microdajus sp. can only be compared to that of the four species where males are known: $M$. aporosus, Microdajus langi Greve, 1965, Microdajus pectinatus Boxshall, Huys and Lincoln, 1989, and $M$. tchesunovi. The present material and $M$. tchesunovi are the only species known to have males with unsegmented protopods of thoracopod 6; the other species have twosegmented protopods on this thoracopod. However, protopods 1-5 of Microdajus sp. extend to an acute point on their lateral margins, whereas they are rounded in M. tchesunovi. The anterior and posterior pits on the cephalothorax of the male of Microdajus sp. show the same pattern as in M. tchesunovi but the number of setae in each pit is fewer in the former species than the latter.

In addition to the differences noted previously, the tantulus larva of Microdajus sp. appears to be the smallest recorded in this genus or of any tantulocaridan species (see Kolbasov and Savchenko, 2010; Petrunina and Huys, 2020). The total length for the tantulus larvae of Gulf of Mexico species is estimated based on a combination of directly measured material (head, SEM preparation) and photographic images (body), the approximate length of approximately 58 $\mu \mathrm{m}$ suggests that these larvae are the smallest ever recorded for any species of tantulocaridan. However, recollection and measurement of an intact tantulus larva is necessary to confirm this potential size record.

The tantulus larvae (Figs. 1D, 2A, B) lack all trunk segments and appendages and are likely developing the early parthenogenetic sacs; however, it is possible that the sacs will develop females inside them, as the trunk segments are lost in larvae in both developmental pathways (see Huys et al., 1993). The complete life cycle of tanulocaridans is in need of investigation and in some ways still remains hypothetical, with details such as metamorphosis of tantulus larvae into adult sexual females and sexual reproduction never having been observed (Mohrbeck et al., 2010; Martinez Arbizu and Petrunina, 2017; Petrunina et al., 2018).

Most species of Microdajus are known from European waters (north-east Atlantic, Mediterranean), with one species being found in the nearby White Sea (Kolbasov and Savchenko, 2010). Only one 
species was previously known outside this region: $M$. aporosus from the Ross Sea (Grygier and Sieg, 1988). Microdajus sp. is the first material referable to this genus to be reported from the western Atlantic and the first tantulocaridan to be described from the Gulf of Mexico or the northwestern Atlantic. In terms of depth distribution, Microdajus sp. was collected from 684-2767 m, which is similar to the ranges for two other Microdajus species: M. gaelicus (897-2884 m) and M.pectinatus (540-2175 m). Most tantulocaridans are from deep sea habitats (see review in Mohrbeck et al., 2010); however, Microdajus sp. represents one of the deepest records for a species in the genus. The deepest record was reported by Mohrbeck et al. (2010) for an unidentified species of Microdajus collected at 5194 m off King George Island, Southern Ocean (see their table 2).

The hosts for Microdajus sp. are specimens of an apparently undescribed species of typhlotanaid, similar in morphology to Typhlotanais kussakini Kudinova-Pasternak, 1970 and T. williamsae Dojiri and Sieg, 1997 (M. Błażewicz, pers. communication). Although other epibionts and parasites (e.g., protozoans, nematodes) are sometimes found associated with tanaids, tantulocaridans have been most commonly reported (Błażewicz et al., 2020) and they are almost always on the front of the host body, possibly due to the tubiculous lifestyle of the hosts (Boxshall and Lincoln, 1987). Typhlotanaids are relatively poorly calcified, which may make them preferred hosts for tantulocaridans (Błażewicz et al., 2020) and these parasites may be more readily observed on tanaids than hosts with more heavily calcified exoskeletons such as isopods (Boxshall and Lincoln, 1987).

\section{ACKNOWLEDGEMENTS}

Thanks to Pernelle Guerrier (Hofstra University) who prepared some of the SEM samples and worked on an early draft of this research and to Magdalena Błażewicz (University of Łódź) for preliminary identification of tanaid hosts. The comments of two anonymous reviewers are appreciated. This research was also supported, in part, by a grant to J.
D. Williams from the National Science Foundation (DBI-1337525).

\section{References}

Błażewicz M.; Stępień, A.; Jakiel, A. and Palero, F. 2020. Tanaidacean diversity in the Northwest Pacific - state of knowledge and future perspectives. p. 461-500. In: H. Saeedi and A. Brandt (eds), Biogeographic Atlas of the Deep NW Pacific Fauna. Sophia, Pensoft.

Boxshall, G.A.; Huys, R. and Lincoln, RJ. 1989. A new species of Microdajus (Crustacea: Tantulocarida) parasitic on a tanaid in the northeastern Atlantic, with observations on M. langi Greve. Systematic Parasitology, 14: 17-30.

Boxshall, G.A. and Lincoln, R.J. 1987. The life cycle of the Tantulocarida (Crustacea). Philosophical Transactions of the Royal Society B, 315: 267-303.

Boxshall, G.A. and Vader, W. 1993. A new genus of Tantulocarida (Crustacea) parasitic on an amphipod host from the North Sea. Journal of Natural History, 27: 977-988.

Greve, L. 1965. A new epicaridean from western Norway, parasite on Tanaidacea. Sarsia, 20: 15-19.

Grygier, M.J. and Sieg, J. 1988. Microdajus (Crustacea: Tantulocarida) parasitic on an Antarctic tanaidacean, and a range extension of $M$. langi Greve. Journal of Natural History, 22: 1495-1505.

Huys, R. 1991. Tantulocarida (Crustacea: Maxillopoda): a new taxon from the temporary meiobenthos. Pubblicazioni della Stazione Zoologica di Napoli I: Marine Ecology 12: 1-34.

Huys, R.; Andersen, P.F. and Kristensen, R.M. 1992. Tantulacus hoegi gen. et sp. nov. (Tantulocarida: Deoterthridae) from the meiobenthos of the Faroe Bank, North Atlantic. Sarsia, 76: 287-297.

Huys, R.; Boxshall, G.A. and Lincoln, R.J. 1993. The tantulocaridan life cycle: the circle closed? Journal of Crustacean Biology, 13: 434-442.

Kolbasov, G.A. and Savchenko, A.S. 2010. Microdajus tchesunovi sp. n. (Tantulocarida, Microdajidae) - a new crustacean parasite of from [sic] the White Sea. Experimental Parasitology, 125: 13-22.

Martinez Arbizu, P. and Petrunina, A. 2017. Two new species of Tantulocarida from the Atlantic deep sea with first CLSM pictures of tantulus larva. Marine Biodiversity, 48: 231-237.

Mohrbeck, I.; Martínez Arbizu, P. and Glatzel, T. 2010. Tantulocarida (Crustacea) from the Southern Ocean deep sea, and the description of three new species of Tantulacus Huys, Andersen \& Kristensen, 1992. Systematic Parasitology, 77: 131-151.

Montagna, P.A.; Baguley, J.G.; Cooksey, C.; Hartwell, I.; Hyde, L.J.; Hyland, J.L.; Kalke, R.D.; Kracker, L.M.; Reuscher, M. and Rhodes, A.C.E. 2013. Deep-sea benthic footprint of the Deepwater Horizon blowout. PLoS ONE 8: e70540.

Ohtsuka, S. and Boxshall, G.A. 1998. Two new genera of Tantulocarida (Crustacea) infesting asellote isopods and siphonostomatoid copepods from western Japan. Journal of Natural History, 32: 683-699. 
Petrunina, A.S.; Høeg, J.T. and Kolbasov, G.A. 2018. Anatomy of the Tantulocarida: first results obtained using TEM and CLSM. Part I: tantulus larva. Organisms, Diversity and Evolution, 18: 459-477.

Petrunina, A.S. and Huys, R. 2020. A new species of Tantulocarida (Crustacea) parasitic on a deep-water cumacean host from the southwestern Atlantic, with a review of tantulocaridan host utilization, distribution, and diversity. Journal of Crustacean Biology, 40: 765-780.

Walter, T. C. and Boxshall, G. 2020. World of Copepods database. Tantulocarida. Accessed through: World Register of Marine Species at: https://www.marinespecies.org/ aphia.php? $\mathrm{p}=$ taxdetails\&id=1083. Accessed on 17 April 2020. 